\title{
O Brasil no âmbito das energias renováveis: biocombustíveis e suas celeumas socioambientais
}

\author{
Charlene de Ávila Plaza' \\ Nivaldo dos Santos ${ }^{2}$ \\ Marcela de Oliveira Santos ${ }^{3}$
}

\section{Resumo}

A reconfiguração de consciência de um meio ambiente sustentável está aquecendo a demanda pelos denominados combustíveis limpos, suscitando várias pesquisas e provocando questionamentos de diversos segmentos sociais. Neste contexto, o presente trabalho se propõe a estudar as seguintes questões: afinal, os biocombustíveis representam soluções efetivas para os problemas climáticos ou um novo problema? Que tipo de matéria-prima deverá preferencialmente ser utilizado em sua produção? Entre a cana-de-açúcar, soja, milho, mamona, celuloses, gramíneas e outros quais seriam as melhores opções para o mercado e para o meio ambiente? Após profunda análise, a partir do método analítico-dedutivo e valendose de pesquisas de campo, dos impactos socioambientais causados pela expansão e pela produção dos biocombustíveis, salientando a emergência nas substituições das matrizes energéticas e mudanças de atitudes para a construção de um futuro

\footnotetext{
${ }^{1}$ Aluna especial do Curso de Doutorado em Desenvolvimento Sustentável - CDS da Universidade de Brasília - UNB. Mestre em Direito na área de Integração e Relações Empresariais pela Universidade de Ribeirão Preto - UNAERP-SP. Professora e pesquisadora da Universidade Paulista - UNIP-GO. Pesquisadora do Núcleo de Patentes e Transferência de Tecnologia-NUPATTE-GO da Universidade Católica de Goiás e da Rede Ibero Americana de Propriedade Intelectual e Gestão da Inovação - RIAPIGI-UCG-GO. Advogada do Escritório Carraro S.S-GO. charlene_plaza@hotmail.com

${ }^{2}$ Doutor em Direito pela Pontifícia Universidade Católica de São Paulo-PUC-SP. Professor Doutor UFG/UCG. Coordenador Geral do Núcleo de Patentes e Transferência de Tecnologia-NUPATTE-GO. Coordenador do Programa de Pós-Graduação Stricto Sensu em Direito, Relações Internacionais e Desenvolvimento.nivaldo@ucg.br

${ }^{3}$ Acadêmica de Direito na Universidade Federal de Goiás.Pesquisadora do Núcleo de Patentes e Transferência de Tecnologia-NUPATTE-GO. Pesquisadora da Rede Ibero Americana de Propriedade Intelectual e Gestão de Inovação-RIAPIGI-GO. ma.osantos@hotmail.com
} 
melhor para a humanidade, os resultados deste estudo apontam que a verdadeira sustentabilidade só deverá emergir se conseguirmos aliar holisticamente as questões ambientais com o modo de produção e consumo da sociedade, repensar na reestruturação das matrizes energéticas que degradem o menos possível o meio ambiente com o auxílio das ciências, da tecnologia e de políticas públicas eficazes a fim de inserir o país na rota do desenvolvimento sustentável, nas dimensões socioeconômicas, ambientais, geográfico-espaciais e político-culturais. Conclui-se que os biocombustíveis não devem ser tratados como um produto viável para a abertura de mercados, fazendo dele somente uma commodity ou alternativa para atender a demanda para o setor automobilístico, mas deverá ser considerado em um contexto mais amplo como o social e ambiental. Além disso, acredita-se numa urgência de tomada de posição do Brasil no cenário. Por outro lado, defende-se que haja um esclarecimento para a população sobre a produção de biocombustíveis e as suas importâncias. Nesse sentido, acreditamos ser este trabalho de grande valor não só para a comunidade acadêmica, mas também para a sociedade como um todo, uma vez que o estudo emerge de questões cotidianas, que ocorrem no seio da sociedade e suas conclusões dizem respeito à necessidade de novas práticas e um novo comportamento diante dos novos problemas e podem ajudar na sua resolução. Além disso, o trabalho apresenta de forma integrada resultados e estudos nunca dantes compilados juntos e se propõe a fazer uma análise ampla, tendo por base várias esferas da sociedade - ambiental, social, política, econômica - o que representa originalidade e novidade.

Palavras-chave: Biocombustíveis. Sustentabilidade. Energias Renováveis. Mercado Internacional. Desenvolvimento socioambiental.

\section{Introdução}

A crescente preocupação mundial com o futuro do meio ambiente e com as desigualdades sociais advindas do atual sistema de desenvolvimento, praticado tanto pelos países em desenvolvimento quanto pelos desenvolvidos, faz com que sejam prementes maiores reflexões sobre as mudanças de paradigmas no que concerne aos novos modelos de desenvolvimento que tenham como metas a sustentabilidade socioeconômica e ambiental. 
A divulgação do $4^{\circ}$ relatório do IPCC (Painel Intergovernamental sobre Mudanças Climáticas), apontando os impactos causados pelo aumento de temperatura do planeta, fez com que comunidades internacionais discutissem o problema de forma mais responsável, com a finalidade de buscarem alternativas viáveis quanto à possibilidade de mudanças e substituições para as atuais matrizes energéticas.

Nesse contexto, os agrocombustíveis seriam, em princípio, soluções viáveis tanto para os problemas climáticos resultantes da queima de energias fósseis, quanto para a finitude das reservas petrolíferas. Entretanto, as mudanças ou substituições das matrizes energéticas, além de seus benefícios, têm seus problemas e consequências. A diversidade e expressivos volumes dos insumos, como oleaginosas e cana-de-açúcar, representam, pelo menos em tese, a redução do custo de produção dos agrocombustíveis a nível competitivo na seara econômica com o petróleo.

Os impactos socioambientais dos biocombustíveis e a maneira como o Brasil deverá se posicionar diante dessas questões no cenário internacional, são premissas fundamentais para emplacar nesse mercado em sua fase inicial, mesmo porque há um amplo consenso entre os países membros da União Europeia para a inclusão de critérios ambientais e sociais na produção dos biocombustíveis, independente de sua origem.

Com os critérios de sustentabilidade a UE (União Europeia) endurecerá as importações de biocombustíveis dos países que não foram capazes de cumprir os tratados internacionais que vão desde o Protocolo de Kyoto até os tratados da OIT (Organização Internacional do Trabalho).

Atualmente, estamos presenciando mais um ciclo econômico - o do biocombustível - que emerge justamente no momento em que o petróleo está no começo do fim, fator esse que contribui para a sua alta de preço no mercado, bem como para questões relacionadas com os problemas ambientais decorrentes do aquecimento global e uma possível alternativa para os biocombustíveis serem a "bola da vez" no cenário internacional.

Como toda grande mudança de paradigmas, o biocombustivel, como possível energia limpa, enfrenta grandes problemas e desafios na seara internacional, uma vez que, com o esgotamento e declínio do petróleo baseado 
em energias fósseis como matriz energética estar cada vez mais crescente, haverá a necessidade de substituição dessa matriz poluente por outras mais benéficas ao meio ambiente.

Para emplacar o sucesso dos biocombustíveis como alternativa renovável, dependerá de muitos fatores, dentre eles a busca do país na capacitação e desenvolvimento de tecnologias para produção na tentativa de retirarmos a "pecha” de que o Brasil apenas exporta bens primários. Mas para que haja a concretização desse objetivo, mister se faz aperfeiçoar tecnologias provenientes de pesquisas e desenvolvimentos para se ofertarem equipamentos com alto valor agregado para o mercado internacional interessado em desenvolver suas biomassas.

O presente artigo tem como finalidade analisar o atual panorama dos biocombustíveis que vivem suas glórias devido à expansão de sua oferta e são apontados como substitutos prováveis do petróleo e seus derivados, devido a seu potencial de mitigar os gases de efeito estufa e serem considerados como energias limpas. No entanto, também vivem seus pesadelos por serem apontados como os vilões no cenário internacional que os acusa de responsáveis pela escassez e elevação dos preços dos alimentos no mundo, cujas plantações desenfreadas de sua matéria-prima como cana-de-açúcar, oleaginosas e outros estão invadindo espaços de plantações voltadas aos gêneros alimentícios.

Sem intuito de fazer apologias em face dos biocombustíveis, constatase que há um aumento de áreas de plantações desses insumos para a sua produção na maioria das regiões brasileiras, sendo a mais problemática a Região Sudeste que, não tendo mais como ocupar espaços para o plantio canavieiro, continua avançando em outras áreas de pastagens e pecuária.

Como pesquisa teórica, será realizada revisão bibliográfica a partir de material publicado, constituído principalmente de livros e revistas especializadas no assunto e outros meios disponíveis, com a finalidade de avaliar criticamente o quadro teórico de referência no intuito de oferecer contribuições originais e maiores discussões da matéria. 


\section{Os paradoxos das energias renováveis e dos biocombustíveis no Brasil}

O Brasil é um país extremamente paradoxal, principalmente quando o assunto é o setor de energias renováveis. Primeiro porque, nos últimos 30 anos, vem galgando posição privilegiada comandando a liderança mundial da produção de etanol, biodiesel e tecnologia biocombustível automotiva, tornando-se um exportador em potencial tanto no que se refere ao produto quanto à sua tecnologia.

Mas ao mesmo tempo em que o governo promove a produção desse combustível e cria normas para que sejam adicionados $2 \%$ do produto ao óleo diesel, este é importado pelo país, fazendo com que se torne um jogo de soma zero, em que os grandes subsídios para as importações destes insumos superem os benefícios sociais da produção do biodiesel e, como consequência ,essas iniciativas se mostrem marginais.

Em segundo lugar, em pleno início de 2008, a sociedade brasileira estava novamente sendo aterrorizada por um indício de um novo apagão de energia. Muito embora a situação não se mostrasse tão grave quanto a de 2001, o mercado continuava cético quanto à possibilidade de o governo fornecer energia elétrica suficiente em 2009.

Terceiro, porque ainda que possua o maior potencial hidrelétrico do mundo, o país perde a oportunidade de liderar uma verdadeira revolução energética, apostando nas usinas termelétricas que dependem de gás natural e combustível fóssil.

Nesse caso, o fantasma do "apagão" também poderá ocorrer nos setores das termelétricas e, sem duvida nenhuma, quem pagará pelos custos do aumento de energia e medidas de racionamento, mais uma vez, será a sociedade brasileira. E por que aventamos mais um colapso de energia desse setor? Pelo simples fato de que não há como atender as demandas para as usinas térmicas, a indústria e o abastecimento de automóveis simultaneamente. 
De acordo com pesquisa realizada pela Princewaterhouse Coopers ${ }^{4}$, o Brasil necessitará investir US\$ 450 bilhões nos próximos 25 anos, isto é, até 2030, para atender a demanda de eletricidade, além de constatarem-se ambiguidades regulatórias quanto à burocracia dos licenciamentos ambientais que travam os necessários dispêndios de capital.

Até o presente momento, o Brasil não criou condições propícias para o desenvolvimento de um mercado de energias renováveis. Apesar de algumas leis e programas terem sido criados como o caso do PROINFA (Programa de Incentivo às Fontes Alternativas de Energia Elétrica), lançado pelo Governo Federal em 2002, eles não foram implementados corretamente, por falhas na definição e em regras claras para o funcionamento desse programa, dificuldades para obtenção de financiamento e barreiras para os empreendedores no que se refere ao acesso ao crédito e a determinados regulamentos institucionais por vezes incompletos, necessitando de maiores discussões.

Assim, a experiência bem sucedida de mais de 40 países mostra que o desenvolvimento do mercado de energias renováveis só acontecerá quando os produtores tiverem garantias de acesso à rede, trabalharem com contratos de longo prazo e tarifas especiais $\left(\right.$ feed $\left.i n^{5}\right)$.

Outros casos que constatam que o Brasil acelera na contramão da história no quesito setor energético, principalmente para a indústria do petróleo, dizem respeito a oito limitações estruturais e principais, apregoadas por Weintraub, Hester e $\operatorname{Prado}^{6}$ :

- Ambiente regulatório burocrático;

- Tributações pesadas, que inclui royalties e taxas específicas para a indústria, a que soma uma questão inadequada das receitas;

- Procedimentos para licenciamento ambiental ineficaz e falta de sinergia entre os órgãos responsáveis;

\footnotetext{
${ }^{4}$ Apud TROSTER, R. L. O deslumbramento com o bom desempenho esconde deficiências de longo prazo. Jornal Valor Econômico, São Paulo, jan. 2008. Caderno Opinião.

${ }^{5}$ Tarifas feed in são tarifas especiais que concedem melhor retorno do investimento, tanto para compradores como para vendedores de energia.

${ }^{6}$ WEINTRAUB, Sidney; HESTER, Annette; PRADO, Verônica R. Cooperação energética nas Américas: entraves e benefícios. São Paulo: Elsevier, 2008. p. 252.
} 
- Dificuldade para obtenção de financiamento para iniciativas privadas nos setores de infra-estrutura e energia, em decorrência de altas taxas de juros.

No que concerne ao setor petrolífero quanto às limitações estruturais e principais, temos:

- O fato de que, oito anos após a entrada em vigor da lei de petróleo que supostamente liberalizou a indústria petrolífera, a Petrobrás ainda desfruta, praticamente, de monopólios na maioria dos segmentos da indústria;

- O fato de a Agência Nacional de Petróleo não dispor dos meios para desincumbir-se de suas responsabilidades para mapeamento da existência de depósitos de petróleo e gás, mediante o uso de levantamento geológico e geodésico;

- Escassez de pessoal brasileiro especializado para as indústrias petrolíferas; e

- Insuficientes atividades de pesquisa e desenvolvimento (P\&D) na indústria do petróleo, exceto as realizadas pela própria Petrobrás através de seu Centro de Pesquisas e Desenvolvimento Leopoldo Américo Miguez de Mello (CENPES). ${ }^{7}$

Nesse diapasão, além dos impostos e contribuições federais e estaduais, que incidem sobre a economia em geral, como ICMS, imposto de renda e de importação, PIS e COFINS, as empresas dos setores de petróleo e gás também estão sujeitas a tributos exclusivos como a Contribuição de Intervenção do Domínio Econômico sobre combustíveis (CIDE Combustíveis), que recai sobre a importação e comercialização.

Além dessas formas tributárias, existem as formas não tributárias de arrecadação governamental pela exploração e produção, não contabilizadas na arrecadação tributária brasileira, os famosos royalties recolhidos mensalmente, como forma de compensação financeira devida ao Estado pelas empresas que exploram e produzem petróleo e gás natural ${ }^{8}$.

${ }^{7}$ WEINTRAUB, Sidney; HESTER, Annette; PRADO, Verônica R. Cooperação energética nas Américas: entraves e benefícios. São Paulo: Elsevier, 2008.

${ }^{8}$ A lei do Petróleo elevou de 5\% para $10 \%$ a alíquota básica dos royalties. Há possibilidades de ser reduzida pela ANP (Agência Nacional do Petróleo) até 5\% considerando aspectos como riscos geológicos e expectativas de produção. Na participação especial (compensação financeira extraordinária introduzida pela lei do petróleo) podem variar as alíquotas de 0 a $40 \%$, incidindo sobre a receita liquida devida pelos concessionários de exploração e produção de petróleo ou gás natural caso ocorra grande volume de produção, grande rentabilidade, ou ambos. 
O setor energético no Brasil é considerado estratégico para a economia e, sobretudo porque há participações diretas e indiretas de várias organizações não governamentais. tais como os institutos de pesquisas e consultorias, as associações comerciais que são atingidas de modo substancial pela ausência de consenso nas searas governamentais e privadas, e as deficiências burocráticas no tocante aos licenciamentos ambientais de projetos de energias que ao final dificultam o crescimento e desenvolvimento do setor.

O fato é que as influências do setor de energia brasileiras não estão adstritas somente no âmbito do Poder Executivo e as linhas que demarcam as competências ente as jurisdições ambientais, federais e municipais são mal definidas, gerando dificuldades e bloqueios dos tais projetos de energia.

O país é um retrato fiel da existência de várias alternativas energéticas, muitos recursos a desenvolver e grandes desafios a superar.

Outra questão que merece destaque é o fato de o governo brasileiro aventar a possibilidade de serem modificadas as regras para o comércio de cessão dos créditos de carbono, mesmo sob pena de os projetos de gerações hídricas, eólicas e de biomassa perderem parte do retorno financeiro.

De acordo com fontes do PROINFA (Programa de Incentivo às Fontes Alternativas de Energia Elétrica, 2008), existem muitos projetos para implantação das energias eólicas e PCHs (Pequenas Centrais Hidrelétricas) no Brasil, sendo que 47 projetos estão em fase de construção. O que concerne aos projetos de energia eólica até o fim deste ano deve estar operando com a capacidade de mais de 800 MW, sendo que é estimado até 2020 responder por 10\% da eletricidade consumida no mundo, meta fixada pela União Europeia, por meio do WEC - World Energy Council (2007).

Na prática, com as supostas mudanças das regras do mercado de carbono no Brasil, quem investir em energias limpas e comercializar esses "papéis" não terá o retorno financeiro que obtinham pelas vendas ou cessões dos referidos créditos, inviabilizando economicamente os projetos de energias renováveis.

E por que a preocupação dos setores envolvidos nos projetos, sobre a possível aprovação das novas regras? 
Uma explicação bem sucinta é dada pelo fato de que os projetos brasileiros desde o início da comercialização internacional dos créditos de carbono utilizam os cálculos para o fator de emissão sob metodologia aprovada pelas Nações Unidas. Em abril de 2007, a Comissão Brasileira decidiu mudar essas bases de cálculo, bem como acrescentá-las de 02 para 04 sub-regiões de acordo com o sistema da ONS (Operador Nacional do Sistema Elétrico).

De acordo com pesquisa técnica realizada pela Consultoria Ecosecurities $^{9}$ (2008, B-1), constatou-se que

com as alterações, as regiões Norte, Nordeste, Sudeste e Centro-Oeste perderão financeiramente, pois seus fatores de emissão foram reduzidos de 0,2611 toneladas de $\mathrm{CO}^{2}$ por $\mathrm{MWH}$ para $0,1043 \mathrm{MWH}$, isto é, a redução de mais da metade nas regiões Sudeste e CentroOeste. Na Região Sul, por sua vez, subiu de 0,2611 MWH para 0,5659 MWH e na região Norte e Nordeste tiveram o fator de emissão quase zerado, gerando um descompasso, pois uma região irá render mais créditos de que a outra.

O imbróglio entre o setor de energia elétrica e as autoridades brasileiras, representa um contrassenso desmedido já que o mercado mundial encoraja as energias limpas para evitar o tão propalado aquecimento global.

Assim, quem investir em energias eólicas no Nordeste não terá direito a crédito de carbono e os projetos do Sudeste e Centro-Oeste sofrerão redução de $60 \%$ do volume de créditos no comércio de carbono.

Sob a ótica desses fatos, os investimentos em projetos de PCHs (Pequenas Centrais Hidrelétricas) e biomassa nas regiões Sudeste e Centro-Oeste e energias eólicas no Nordeste se tornarão inviáveis em termos de retorno financeiro, caso essas regras de subdivisão venham a imperar. Mais uma vez, o Brasil na contramão da história.

${ }_{9}^{9}$ País pode ser responsável por 10\% dos negócios entre 2008 e 2012, que devem movimentar US\$ 10 bi por LOJUDICE, Marcelo. Valor econômico, 2008. Disponível em: <http:// dabdoub-labs.com.br/Cotas_de_Carbono.htm>. Acesso em: 10 abr. 2008. 


\section{Os desafios dos biocombustíveis no cenário internacional: breves análises}

Adentramos na era da biocivilização, assistindo ao declínio compulsório da civilização do petróleo com o diferencial de possuirmos criatividade e um alto potencial de biomassa que, com a ajuda da biotecnologia, poderá ser revertida em alimentos, materiais de construções ${ }^{10}$, adubos verdes, biocombustíveis, fibras e plásticos verdes, fármacos e cosméticos, ampliando os recursos da biomassa e os produtos dela derivados.

A biotecnologia moderna tem sido empregada em vários cultivos de oleaginosas, como na soja, no milho e algodão, totalizando mais de 114,3 milhões de hectares cultivados no mundo ${ }^{11}$, além de que será uma condutora para a abertura de um leque gigantesco sobre os produtos derivados da biomassa, aumentando a produtividade primária do país.

Nesse raciocínio, o biocombustivel celulósico, inovação tecnológica incipiente no Brasil que se baseia em tecnologias de grande monta, permitirá para o país desenvolver uma base de matéria-prima totalmente diferente da atual e, quem sabe, promissora, visto que todos os resíduos vegetais são aproveitados para a produção do etanol celulósico.

Uma nova situação e uma maioridade dos biocombustíveis podem ser analisadas com foco em três fatores: primeiro, a crença de vários geólogos que o pico da produção de petróleo vai acontecer dentro de dez a vinte anos, não significando que o produto irá desaparecer, mas que hoje, aparentemente, as novas reservas não compensam a extração, ressurgindo um novo cenário de esgotamento das reservas de petróleo que poderá durar um século sem contar

\footnotetext{
${ }^{10}$ Concreto verde - aproveitamento das cinzas da queima do bagaço de cana que sobram das caldeiras e geradores para a produção de energia elétrica para abastecimento das usinas. O concreto de desenvolvimento sustentável é fruto das preocupações mostradas pelo IPCC e Protocolo de Kyoto, no que tange ao aquecimento global e principalmente para atender a demanda das indústrias cimenteiras que produzem grandes quantidades de gás carbônico. FAPESP. Concreto Verde. Marcos de Oliveira. Resíduos agrícolas podem diminuir o uso de cimento e reduzir a emissão de dióxido de carbono, abril, 2008, edição n. 146, p. 36-37.

${ }^{11}$ ISAAA apud ODA, Leila M.; FAUSTINO, Vivian Cristina; BORGES, Kelly C. Biotecnologia e impactos na produção de biodiesel. Rio de Janeiro: ANBIO, 2008.
} 
que seus preços não param de subir, atualmente a 100 dólares o barril, tornando os biocombustíveis competitivos. Segundo, o fator geopolítico com os custos cada vez maiores que os dos EUA e dos seus aliados têm na manutenção das linhas de abastecimento a partir do Oriente Médio, surgindo a possibilidade de investimentos nas alternativas renováveis, do que essa situação de abastecimento atual; e terceiro, é o problema ambiental, muito embora seja essa questão antecedente a esses fatores, o fato é que, mesmo que fosse realizado integralmente o Protocolo de Kyoto, ainda seria altamente insuficiente em termos da redução das emissões de gases de efeito estufa ${ }^{12}$.

Portanto, cresce o interesse pelo Brasil na comunidade internacional que possui uma experiência há mais de trinta anos com o Programa Pró-álcool, além da perspectiva futura de transformar o etanol da cana em uma nova commodity, com um balanço energético melhor do que os derivados do milho; por outro lado, o mesmo não acontece com o biocombustivel derivado dessa produção americana que vem sendo atacado pela opinião pública internacional como o grande vilão para a escassez dos alimentos, fazendo com que o etanol brasileiro tenha maiores vantagens em face ao etanol americano sob três aspectos: evolução da área plantada, alta nos preços do petróleo e a mitigação de gás carbônico.

O consumo do combustível derivado do milho, de acordo com pesquisa da Associação dos Combustíveis Renováveis ${ }^{13}$, cresceu de 20,35 bilhões de litros em 2006 para 26, 9 bilhões em 2007, sendo que a capacidade produtiva americana obteve em 2006 um salto de 16,4 bilhões de litros para 20,79 bilhões em 2007, atingindo em 2008 27,36 bilhões de litros em produção.

A situação se torna preocupante sob o ponto de vista da área cultivada do milho pelos EUA, pois não há possibilidade de se expandir para novos cultivos e em consequência há uma justaposição dessa cultura em detrimento das outras como o caso da soja, algodão e arroz, provocando o aumento dos preços que sempre são relacionados com o aumento do petróleo.

${ }^{12}$ SACHS, J. D. Technological solutions not political change, key to ending African poverty. Daily Yomiuri, Tóquio, p. 52, 2004.

${ }^{13}$ TROSTER, R. L. O deslumbramento com o bom desempenho esconde deficiências de longo prazo. Jornal Valor Econômico, São Paulo, jan. 2008. Caderno Opinião. 
A situação é idêntica para os países da União Europeia que apostam no biocombustível derivado da canola, que cresceu em patamares de 3,8\% entre 2000/08, originando uma queda nas produções de outras culturas como a cevada e sorgo.

Diante desse imbróglio, o Brasil pode ser seriamente afetado pela maneira de como está sendo feita a condução especulativa dos mercados, principalmente os europeus, que insistem em comparar o etanol americano com o etanol brasileiro, impondo barreiras para a exportação dos biocombustíveis, desrespeitando as regras da OMC (Organização Mundial do Comércio) para justificar a carência e a crescente alta de alimentos no mundo.

Atualmente, o Brasil é responsável por 44\% das importações de etanol para a União Europeia, seguido pelo Paquistão com $10 \%{ }^{14}$, desejando ampliar suas exportações para a comunidade até 2009. Um dos obstáculos que o Brasil enfrentará para concretizar esses objetivos e implementar um acordo de livre comércio entre a União Europeia e o Mercosul na negociação sobre os biocombustíveis é que várias indústrias de etanol estão sendo introduzidas na Europa, em específico, 06 usinas na França, 03 na Alemanha, caminhando para a mesma direção a Espanha e a Suécia, além de que está condenado a se adequar às regras do jogo internacional nos aspectos sociais e ambientais ou não obterá espaço no mercado externo.

As novas regras possivelmente poderão inviabilizar o crescimento das vendas dos biocombustíveis brasileiros para o Bloco Europeu. Por quais motivos?

Primeiro, as bases da nova regra estabelecerá um biocombustível ambientalmente sustentável; isso significa que não poderá ser obtido a partir de matériasprimas cultivadas em áreas úmidas ou de florestas. Com essas regras, o bloco exigirá provas de eficiência energética na produção, defesa da biodiversidade e certificação (selo de certificação), além de outras medidas, como a adoção para enquadrar a floresta tropical no intuito de coibir o desmatamento.

Outro critério do bloco europeu visa limitar emissões de gases de efeito estufa, compreendendo desde a produção do etanol, transporte e processamento, por meio do controle denominado “poupança gás” na utilização do biocombustível.

\footnotetext{
${ }^{14}$ WEINTRAUB, Sidney; HESTER, Annette; PRADO, Verônica R. Cooperação energética nas Américas: entraves e benefícios. São Paulo: Elsevier, 2008. p. 252.
} 
Desse modo, as exigências irão além do processo de produção. Se houver desmatamento na produção do bioetanol, deverão ser contabilizadas as emissões provocadas pela mudança do uso de terra, inviabilizando comercialmente a sua exportação para os países componentes do bloco.

O terceiro critério concerne à proibição do bicombustível originado de matérias-primas obtidas de florestas não afetadas pelas ações antrópicas ou áreas protegidas. Se esses critérios forem aceitos, há grandes possibilidades do etanol brasileiro não atender às exigências de Bruxelas, principalmente no que concerne à redução de emissões de gases de efeito estufa na comparação com a gasolina, mesmo porque deverá ter uma garantia de redução mínima de 35\% dos gases e o Parlamento europeu exige 50\% de redução.

No entanto, antes da União Europeia sacrificar as importações dos biocombustíveis brasileiros, seria interessante repensar com mais seriedade sobre focar as suas restrições ao óleo de palma produzido pela Indonésia à custa de devastações das poucas florestas existentes no país, do qual a Alemanha é um grande importador, como também analisar a baixa eficiência energética do etanol derivado do milho dos EUA em termos comparativos com o etanol do Brasil.

Caberá ao Brasil, como líder das exportações mundiais de combustível, regulamentar a produção, exigindo fiscalização e cumprimento das leis aplicáveis a esse setor. Resumindo: é necessário vontade política e principalmente a promoção da ação e acesso a tecnologias apropriadas e, por outro lado, o país deverá convencer o mercado internacional que a interface entre biocombustíveis e a crise de alimentos vai muito mais além do que a expansão da oferta do produto.

\section{As celeumas socioambientais em busca da sustentabilidade no setor dos agrocombustíveis}

Vários dilemas enfrentam o modelo agrícola brasileiro, baseado na monocultura para exportação de agrocombustíveis, apontados por movimentos sociais e ambientalistas como modelo gerador de desigualdades no campo, entraves à reprodução social de populações tradicionais, impactos sobre a agricultura familiar e mudanças no padrão de produção agrícola por ela extensivamente ocupada. 
A produção agrícola na forma de monocultivo é, por si só, prejudicial para a natureza e para o meio ambiente, porque destrói outras formas de plantas e a biodiversidade, alterando o equilíbrio das chuvas e aumentando as temperaturas.

Historicamente, a indústria sucroalcooleira, guardadas as devidas proporções, foi uma indústria caracterizada pela concentração de terras, desrespeito às leis trabalhistas e perpetuação da pobreza social.

Sachs ${ }^{15}$, ao sugerir sobre uma maior reflexão quanto a harmonizar os aspectos sociais, ambientais e econômicos diz que:

Para compatibilizar os objetivos sociais, econômicos e ambientais, temos que nos dedicar ao que chamaria de um jogo de harmonização. Neste jogo, temos que mudar, por um lado, os padrões da demanda e, por outro lado, os padrões da oferta. Estes últimos são mais fáceis de manejar e vão nos remeter ao problema dos recursos naturais, aos tipos de energia, às tecnologias e á localização espacial das produções, porque as mesmas produções têm impactos ambientais diferenciados, segundo o lugar onde elas acontecem.

A mudança do padrão da demanda é logicamente a variável mais importante nesse jogo de harmonização, porém, ela passa pela modificação dos estilos de vida e dos padrões de consumo, assim é uma variável extremamente difícil de manipular e exige antes um enorme esforço de educação. As margens de manobra seriam muito maiores se estivéssemos vivendo num mundo mais igualitário.

A expansão da monocultura canavieira é facilitada por um mercado de terras pouco ordenado jurídico e socialmente, concentrando a propriedade e inviabilizando as práticas pela agricultura familiar de subsistência.

Apesar das grandes expectativas criadas pelo PNPB - Programa Nacional de Produção e Uso -, no que tange ao biodiesel, para impulsionar a agricultura familiar com objetivo da promoção da inclusão social e a redução das disparidades regionais, os resultados não estão acontecendo, principalmente no caso do plantio da mamona.Mais em específico, na região do semi-árido, as oleaginosas cultivadas são a mamona, o girassol, o amendoim, o algodão e o pinhão manso, ainda que a legislação somente preveja a mamona e o dendê.

${ }^{15}$ SACHS, J. D. Technological solutions not political change, key to ending African poverty. Daily Yomiuri, Tóquio, p. 52, 2004. 
De acordo com o relatório CMA, O Brasil dos Agrocombustíveis ${ }^{16}$ "a pífia evolução da área plantada de mamona desde 2004 é um indicador da resposta". O Relatório ressalta que a safra 2007/08 obteve alta de apenas 1.7\% em relação à safra anterior e que, apesar dos esforços nas esferas governamentais, a cultura não emplacou nem junto ao agricultor familiar, nem na indústria de biodiesel.

Ao mesmo tempo em que muitos produtores familiares se integram à produção de mamona, outros abandonam a cultura ou resistem em ampliar as áreas cultivadas, premidos por vários empecilhos, como a dificuldade de encontrar sementes certificadas, equipamentos, insumos, crédito e assistência técnica com o agravante de que a mamona cultivada é plantada do mesmo modo que era há 30 anos, sem análise e recomposição dos solos, técnicas de convivência com irregularidades climáticas e adubação química e orgânica.

O MDA ${ }^{17}$ relata que as plantações de mamona no início desse ano apenas $15 \%$ do biodiesel virão de matérias primas fornecidas por pequenos agricultores, demonstrando que os projetos de inserção do pequeno agricultor no Programa Nacional de Biodiesel ainda são bastante incipientes além de que os mecanismos de controle e fiscalização do "Selo Combustível Social" não estão sendo capazes de impedir que a produção da agricultura familiar seja utilizada como fachada para obtenção de incentivos fiscais. Trocando em miúdos, o que acontece é a existência de um monopólio de uma indústria denominada "Ecodiesel" que atua no negócio de produção de mamona para biodiesel e a existência de outras indústrias que contratam agricultores familiares para aquisição e produção desse insumo, somente o fazendo para adquirir o Selo Combustível Social ou poder participar de leilões promovidos pela Petrobrás vez que é exigido tanto pelo Selo quanto pela estatal que as usinas adquiram produtos derivados da produção familiar.

Assim, a inserção da agricultura familiar na cadeia do biodiesel irá implicar reestruturações de seus sistemas de produção, uma maior intensidade tecnológica e uma maior dependência do mercado.

${ }^{16}$ CMA. Relatório anual 2008: o Brasil dos agrocombustíveis: os impactos das lavouras sobre a terra e o meio ambiente e a sociedade. São Paulo: Eskenazi, 2008. p. 39.

${ }^{17}$ MDA. Biodiesel no Brasil: resultados socioeconômicos e expectativa futura. Brasília, 2008. Disponível em: <http://www.mda.gov.br/saf/index.php?sccid=294>. Acesso em: 10 abr. 2008. 
Mas a equação não é tão simples assim, porque os modos de produção, alterando a estrutura produtiva familiar sobre as pequenas e médias propriedades rurais para a expansão de monoculturas, são um problema, pois reconfiguram, os espaços geográficos, ocasionando pressão nos modos de vida e nas atividades rurais. Adicionalmente a esse fator, necessitam-se também de melhores políticas públicas a fim de que se permitam melhorias em seus sistemas produtivos e que impeçam que a cultura de oleaginosa se faça de forma subordinada à grande propriedade.

Desse modo, a realidade observada só tomará novos contornos se forem instituídos melhores instrumentos de políticas públicas de apoio no intuito de fortalecer a agricultura familiar e seus sistemas produtivos.

\subsection{Impactos socioambientais dos biocombustíveis no Brasil}

Conhecer os possíveis impactos da questão sobre a expansão e produção dos biocombustíveis é de fundamental importância para nosso país, que está construindo o seu futuro, e para o planeta, que vive as agruras do aquecimento global capazes de comprometer a nossa geração e as que estão por vir.

O primeiro impacto indireto é o arrendamento de terras pelos produtores das grandes empresas para ampliação de sua produção, desencadeando alterações nos tipos de produção, na disponibilidade de empregos, nos fluxos migratórios desmedidos nas cidades, na oferta de alimentos e na demarcação de terras para a reforma agrária.

A opção pela mão de obra migrante é uma estratégia para baixar os custos de produção do setor sucroalcooleiro, vez que, grande parte da admissão é feita sem registro em carteira por atravessadores, ou seja, contratantes ilegais denominados "gatos".

Esses trabalhadores, muitas vezes, vivem em condições subumanas, alojados em casas dentro dos canaviais ou nas periferias das cidades, longe de seus familiares e sem acesso às redes locais de proteção, como sindicatos, pastorais da terra, além de que existem reminiscências de trabalho escravo e trabalho não remunerado. 
A colheita manual da cana é responsável por $60 \%$ do contingente de trabalhadores ${ }^{18}$, apesar de que essa prática esteja com os dias contados, tendo prazo para terminar em 2017, ameaçando o emprego de muitos trabalhadores canavieiros e criando dessa maneira um processo contraditório de geração de empregos pela expansão da área plantada e a criação do desemprego pela mecanização da colheita. Cada colheitadeira de cana poderá substituir de 80 a 120 trabalhadores, dependendo das condições de operação.

No Estado de São Paulo, segundo Rodrigues ${ }^{19}$, cerca de $30 \%$ do corte de cana já esta sendo mecanizado sendo que o objetivo é que até 2014 o seja em 100\% da colheita da cana.

Em uma reportagem no Jornal Gazeta Mercantil20 (2007), há relato de que a Case International Haverst - CHI, empresa que produz máquinas e motores, estimou a produção em 2007 para 550 unidades, ante 265 unidades em 2006. Para 2008, esperam produzir $40 \%$ a mais, avaliando que entre 2007 e 2008 sejam produzidas mais colheitadeiras de cana do que nos últimos dez anos.

Mas, até 2017, muitos problemas continuarão a existir com esses trabalhadores migrantes, como doenças e mortes advindas das pressões por maior produtividade no corte de cana.

As mortes por excesso de trabalho demonstram uma dicotomia interna das indústrias sucroalcooleiras que, por um lado, empregam os mais modernos equipamentos de produção e, de outro, escravizam o trabalhador por intermédio de sistemas de desempenhos sobre regras de proporção e equivalência entre metros e toneladas de canas cortadas, controles de ausências e consultas médicas burladas.

${ }^{18}$ GONÇALVES, Daniel Bertoli. Mar de canola, mar verde? Dilemas do desenvolvimento sustentável na produção canavieira paulista. 2005. Tese (Doutorado em Engenharia de Produção) - Centro de Ciências Exatas e de Tecnologia, Universidade Federal de São Carlos, São Carlos, 2005.

${ }^{19}$ RODRIGUES, Márcio. Usinas terão até 2017 para colher cana sem queimadas em São Paulo. Folha online, São Paulo, 2007. Disponível em: <www.folhaonline.com.br $>$. Acesso em: 10 abr. 2008.

${ }^{20}$ CASE acelera a produção de colheitadeiras. Gazeta Mercantil, 2007. Disponível em: http:// indexet.investimentosenoticias.com.br/arquivo/2007/04/19/31/Case-acelera-producaode-colheitadeiras.html. Acesso em 10 de abril de 2008. 
O setor continua, embora com menos intensidade, a registrar casos de trabalho infantil e trabalho escravo devido à precariedade das relações de trabalho entre os dois atores. Muitas vezes, crianças são integradas a esse regime por influência da própria família no intuito de aumentar a produtividade e atingir as cotas definidas para cada trabalhador remunerado no corte da cana.

Apesar de serem flagrantes esses acontecimentos, nos últimos anos, a fiscalização vem se intensificando pelas ações conjuntas do Ministério Público e o grupo móvel, bem como a ratificação pelo governo brasileiro das recomendações da Organização Internacional do Trabalho - OIT, que proíbem as formas precárias de trabalho infantil, definindo a idade mínima de 18 anos para a inserção em atividades penosas. Dessa força tarefa, aparentemente observa-se uma queda do trabalho infantil na última década, mas, por outro lado, o setor continua registrando casos de trabalhadores em regime de cativeiro em condições análogas a de escravo.

Em contrapartida, existem usinas modernas que, no intuito de participarem do mercado internacional, procuram se adequar às condições de trabalho e introduzem programas especiais para educação, alimentação e preparação física dos trabalhadores a fim de não terem de suportar os pesados encargos com processos trabalhistas e greves, acarretando perda na produtividade industrial e, o motivo mais importante, perda da imagem corporativa no mercado externo.

Existem avanços nesse setor? Aparentemente nos parece que sim; mas, mesmo considerando esses avanços, pouca atenção tem-se demonstrado pelos problemas sociais nos atores envolvidos na cadeia produtiva, predominando ainda hoje a lógica da precarização do trabalho mesmo com todos os avanços tecnológicos e o desrespeito às legislações e tratados internacionais sobre o trabalho. Além desses impactos, outros necessitarão de novos modais para sua análise, quais sejam:

-O crescimento do controle estrangeiro sobre a terra para a produção de matéria-prima para a produção do etanol; questão que deverá ser encarada pelos nossos governantes com mais seriedade, com amplos debates entre toda a sociedade e os que administram em nosso nome o país.

-A contaminação das águas e do solo pelos agrotóxicos e os herbicidas, assim como a saturação dos solos pelos fertilizantes 
nitrogenados compostos pelo óxido nitroso $\left(\mathrm{NO}^{2}\right)$ que é 310 vezes mais poluente que o dióxido de carbono requerendo conscientização e mobilização de forças regionais nem sempre ativas. Nesse caso, estamos falando de problemas ambientais locais não menos relevantes.

Afirmam Cardoso, Machado e Pereira ${ }^{21}$ que "o nitrogênio ativo não pode ser confundido com o gás nitrogênio, que é o principal componente da atmosfera e é considerado inerte", e aquele que, por sua vez, é responsável por provocar problemas ambientais locais e regionais como a chuva ácida, a contaminação de águas e ainda com grande potencial para afetar a biodiversidade de florestas naturais.

Os mesmos autores apregoam que a cultura da cana-de-açúcar ${ }^{22}$ atua diretamente ou indiretamente em quatro mecanismos de formação e dispersão de nitrogênio ativo no ambiente, quais sejam:

-Arraste pelas águas das chuvas do nitrogênio contido em adubos;

-Ação de microorganismos no solo, transformando parte do adubo aplicado em gases;

-Produção de nitrogênio ativo por bactérias existentes em raízes de leguminosas que transformam o nitrogênio inerte do ar em nitrogênio ativo;

${ }^{21}$ CARDOSO, Arnaldo Alves; MACHADO Cristiane de Melo Dias; PEREIRA, Elisabete Alves. Biocombustível: o mito do combustível limpo. Araraquara, SP: IQA/UNESP, 2008. p. 8 .

22 A queima da palha da cana, só no Estado de São Paulo, emite por ano cerca de 46.000 t. de nitrogênio ativo para a atmosfera. Este nitrogênio ativo produzido pela queima de folhas da cana que contém nitrogênio na sua estrutura e também pelo calor gerado que converte o nitrogênio em ar, em $\mathrm{NO}^{2}$. O dióxido de nitrogênio tem também propriedades de catalisar reações atmosféricas em presença de luz solar, as quais formam, entre outros, o ozônio $\left(\mathrm{O}^{3}\right)$. Este composto que filtra as radiações solares quando presentes na alta atmosfera, região conhecida como camada de ozônio, é um grande vilão quando formado na baixa atmosfera. A queima da palha de cana emite, além de $\mathrm{NO} \mathrm{E} \mathrm{NO}^{2}$, outros gases. Pelo aspecto da química ambiental, para chamar o álcool ou outro combustível de combustível limpo, é necessário esconder muita sujeira debaixo do tapete, vez que a emissão de nitrogênio ativo, nenhuma diferença faz o tipo de combustível utilizado, já que os gases $\mathrm{NO}$ e $\mathrm{NO}^{2}$ sempre são emitidos. (CARDOSO, Arnaldo Alves; MACHADO Cristiane de Melo Dias; PEREIRA, Elisabete Alves. Biocombustível: o mito do combustível limpo. Araraquara, SP: IQA/UNESP, 2008. p. 9-13). 
-Formação de gases nitrogenados como produto da combustão de qualquer combustível.

Muito há que se fazer para minimizar os impactos socioambientais no Brasil, principalmente no sentido de pressionar a redução de desigualdades no setor canavieiro em busca da verdadeira sustentabilidade econômica, social e ambiental para a produção dos biocombustíveis.

Vistos por empresários e governos como uma alternativa para a mitigação das mudanças climáticas, os biocombustíveis são considerados como portadores das benesses da energia limpa. Mas precisamos nos questionar até que ponto o considerado salvador da pátria e do clima é renovável. Será que não continuamos emitindo poluição para a atmosfera e maximizando o aquecimento global, vez que o conceito de combustível limpo se restringe ao elemento carbono? A derrubada de florestas e a ocupação dos biomas nacionais para o plantio de cana e grãos criariam uma "divida de carbono" que poderá durar séculos para ser compensada. $\mathrm{O}$ fato é que a utilização de qualquer combustível em processo de combustão afeta o meio ambiente, seja ele biocombustível ou um combustível fóssil.

\section{Considerações finais}

Estamos adentrando na fase final da civilização do petróleo em que por vários séculos as energias fósseis dominaram o mundo, primeiro pelo carvão e depois pelo petróleo e iniciando uma nova era - a nova civilização da biomassa que será capaz de conciliar os grandes problemas que afligem a humanidade como a produção de alimentos para o homem, bem como em uma infinidade de produtos derivados dela, os biocombustíveis, materiais para construção e fármacos entre outros.

Os biocombustíveis, por sua vez, não devem ser tratados como um produto viável para a abertura de mercados, fazendo dele somente uma commodity ou alternativa para atender a demanda para o setor automobilístico e sim deverá ser considerado em um contexto mais amplo como o social e ambiental. No contexto social, porque poderá elevar o nível de vida da sociedade com possibilidades de trabalho e renda, com a inserção do pequeno produtor na cadeia produtiva; e no contexto ambiental, na capacidade de reduzir os impactos adversos ao meio am- 
biente por ser uma energia mais limpa do que outras que ainda são empregadas em grandes escalas, tanto pelos países em desenvolvimento quanto pelos países desenvolvidos.

O Brasil necessitará se posicionar diante do cenário internacional para retirar o estigma de que é um país excludente, com altas concentrações de rendas e destruidor de seus recursos naturais, porque, atualmente, o elemento chave é a sustentabilidade que busca um desenvolvimento que atenda não só as questões de energia em si, mas a toda cadeia de inclusão social e ambiental, pois nem todo desenvolvimento pode ser considerado como progresso no contexto de desenvolvimento sustentável.

Por sua vez, o país destaca-se pela elevada participação nos setores de biocombustíveis por sua possível sustentabilidade, como também por possuir condições naturais excelentes e alto potencial para a produção de energia por meio da biomassa. De acordo com a Embrapa ${ }^{23}$, o país possui 90 milhões de hectares disponíveis para agricultura de oleaginosas destinadas à produção de biodiesel e com um diferencial que é ser o único país a produzir etanol de canade-açúcar.

A produção de biocombustíveis deve ser esclarecida para todos os cidadãos, maiores debates devem ser propostos entre os setores envolvidos nas cadeias produtivas e analisados, em um contexto macro, os aspectos positivos e negativos, principalmente as barreiras comerciais que atualmente vêm sendo impostas pela comunidade europeia com o intuito, pelo menos em tese, de proteger o meio ambiente.

O país está caminhando para que seja garantida a sustentabilidade ecossocioeconômica dos biocombustíveis por meio de empresas responsáveis e institutos de pesquisas competentes em parcerias com institutos internacionais e governos locais. Quanto às implicações ambientais, é primordial fazer um estudo do potencial valorativo dos biocombustíveis respeitantes à sua sustentabilidade na biodiversidade, na poluição dos solos e da água e na disponibilidade de terras para sua expansão.

${ }^{23}$ EMBRAPA. Biocombustíveis no Brasil. Brasília, 2007. Disponível em: <http://www.aquecimento.cnpm.embrapa.br/conteudo/brasil_biocombustiveis.htm. Acesso em: 22 abr. 2008. 
No que tange às implicações econômicas, deverão ser sobrepesados os aspectos tributários, isto é, fatores que incluam a tributação das externalidades de modo a favorecerem tecnologias limpas, subsídios e eficiência energética no contexto de promoção do bem estar social.

Certamente, vários pontos de vista emergirão para essas questões, mas é melhor que assim seja, visto que o confronto de opiniões irá facilitar para harmonizarmos as melhores soluções.

\section{Brazil in the renewable energies' scope: the biofuel and the socio- environmental discussion}

\section{Abstract}

The reconfiguration of awareness of a sustainable environment is heating up the demand for so-called clean fuels, raising research and causing several inquiries from various social segments. In this context, this paper is to consider the following questions: after all, biofuels are effective solutions to the climate problem or a new problem? What kind of raw material should preferably be used in their production? Among the cane sugar, soybean, corn, castor oil, cellulose, grasses, and what are the best options for the market and for the environment? After thorough analysis, from the analytical-deductive method and drawing on field research, social and environmental impacts caused by the expansion and production of biofuels, noting the emergence of substitutions in the energy mix and changes in attitudes to build a future better for mankind, the results show that true sustainability will only emerge if we combine holistically environmental issues with the mode of production and consumption society, rethink the restructuring of the energy matrices that degrade the least possible disruption to the environment with the aid of science, technology and public policies in order to enter the country on the road to sustainable development in the dimensions of socioeconomic, environmental, geo-spatial and politico-cultural. It is concluded that biofuels should not be treated as a viable product to market opening, making it a commodity or only alternative to meet the demand for the automobile sector, but should be considered in a broader context, both social and environmental. Moreover, it is believed an urgent position of Brazil in the scenario. On the other hand, argues that there is an explanation 
for the population on the production of biofuels and their importance. We therefore believe that this work of great value not only to the academic community, but also for society as a whole, since the study emerges from everyday issues that occur in society and their conclusions relate to the need for new practices and a new behavior when facing new problems and can help in its resolution. In addition, the paper presents an integrated and research results never before collected together and set out to do a comprehensive analysis, based on various spheres of society environmental, social, political, and economic - that's originality and novelty.

Keywords: Biofuels. Sustainability renewable energies. International market. Social and environmental development.

\section{Referências}

CARDOSO, Arnaldo Alves; MACHADO Cristiane de Melo Dias; PEREIRA, Elisabete Alves. Biocombustível: o mito do combustível limpo. Araraquara, SP: IQA/UNESP, 2008.

CMA. Relatório anual 2008: o Brasil dos agrocombustíveis: os impactos das lavouras sobre a terra e o meio ambiente e a sociedade. São Paulo: Eskenazi, 2008.

EMBRAPA. Biocombustíveis no Brasil. Brasília, 2007. Disponível em: <http://www. aquecimento.cnpm.embrapa.br/conteudo/brasil_biocombustiveis.htm $>$.Acesso em: 22 abr. 2008.

GONÇALVES, Daniel Bertoli. Mar de canola, mar verde? Dilemas do desenvolvimento sustentável na produção canavieira paulista. 2005. Tese (Doutorado em Engenharia de Produção)-Centro de Ciências Exatas e de Tecnologia, Universidade Federal de São Carlos, São Carlos, 2005.

MAPA. Participação do estado de Goiás na produção sucroalcooleiras. Brasília: MAPA, 2007.

MDA. Biodiesel no Brasil: resultados socioeconômicos e expectativa futura. Brasília, 2008. Disponível em: <http://www.mda.gov.br/saf/index.php? sccid=294>. Acesso em: 10 abr. 2008. 
ODA, Leila M.; FAUSTINO, Vivian Cristina; BORGES, Kelly C. Biotecnologia e impactos na produção de biodiesel. Rio de Janeiro: ANBIO, 2008.

RODRIGUES, Márcio. Usinas terão até 2017 para colher cana sem queimadas em São Paulo. Folha online, São Paulo, 2007. Disponível em: <www.folhaonline.com. br>. Acesso em: 10 abr. 2008.

SACHS, J. D. Da civilização do petróleo a uma nova civilização. Revista Estudos Avançados, São Paulo, n. 55, p. 2-11, 2005.

SACHS, J. D. Technological solutions not political change, key to ending African poverty. Daily Yomiuri, Tóquio, p. 52, 2004.

TROSTER, R. L. O deslumbramento com o bom desempenho esconde deficiências de longo prazo. Jornal Valor Econômico, São Paulo, jan. 2008. Caderno Opinião.

WEINTRAUB, Sidney; HESTER, Annette; PRADO, Verônica R. Cooperação energética nas Américas: entraves e benefícios. São Paulo: Elsevier, 2008. 